\title{
Por amor à filosofia... e ao mundo que se abre com ela
}

\author{
Edna Olimpia da Cunha' \\ Julia Krüger² \\ Sammy W. Lopes 3 \\ Walter Omar Kohan ${ }^{4}$
}

\begin{abstract}
Resumo
Trata-se de uma reflexão sobre as potencialidades manifestas pelo Projeto "Em Caxias a filosofia en-caixa?" - idealizado e dirigido pelo Núcleo de Estudos de Filosofias e Infâncias (PROPEd-UERJ) - a partir dos encontros promovidos com duas escolas públicas do Município de Duque de Caxias, RJ, destacadamente com discentes da EJA da Escola Municipal Joaquim da Silva Peçanha; visando suscitar experiências filosóficas de pensamento, minimamente diretivas, orientadas a convidar o outro (com Heráclito), a elaborar entendimentos próprios sobre si, o mundo e a vida compartilhando-os e discutindo-os com um coletivo. Evidencia também o sentido da aposta política inerente à concepção do projeto e ao modo de condução da dinâmica de trabalho empregada para reger os encontros, demonstrando seu valor diferencial e, sob certa perspectiva, educativo.
\end{abstract}

Palavras-chave: Filosofia; Experiência; Pensamento; Educação.

\section{For love to Philosophy... and for the world that opens with it.}

\begin{abstract}
It is a reflection about the potentialities of the project "Em Caxias a filosofia em-caixa?"conceived and directed by the Philosophical Studies Center of childhood (EDU-UERJ)- in the meetings promoted with two public schools of the Duque de Caxias municipality, RJ, notably with students of the Municipal School of adult and youth education Joaquim da Silva Peçanha; in order to give rise to philosophical thought experiments, minimally guided, oriented (from Heraclitus) to invite the other to develop your own understanding about themselves, the world and the life, sharing them and discussing them with a collective. It highlights also the sense of policy bet, inherent in the Project design and the way of driving the work dynamics employed to conduct meetings, demonstrating its differential value and, under certain perspective, educational.
\end{abstract}

Keywords: Philosophy; Experience; Thinking; Education.

\footnotetext{
'Professora da Escola Municipal Joaquim da Silva Peçanha, Duque de Caxias, RJ. Email: dinha2rj@hotmail.com

2 Mestranda em educação pela UERJ. Email: jukruger13@gmail.com

3 Professor Adjunto da UERJ. Email: samwlopes@gmail.com

4 Professor Titular da UERJ. Pesquisador CNPq/FAPERJ. Email: wokohan@gmail.com
} 
Fazemos parte do Projeto "Em Caxias a filosofia en-caixa?". 5 Realizamos atividades em duas escolas públicas de Duque de Caxias e na Universidade do Estado do Rio de Janeiro (UERJ). Nas escolas fazemos experiências de pensamento com crianças de educação infantil, ensino fundamental e educação de jovens e adultos. Uma vez por mês os estudantes das escolas participam de experiências de filosofia na UERJ; nestas, estudantes e professores das escolas e da universidade se encontram para pensar juntos e tentar construir noções comuns. O que narramos a seguir tem a ver com a última atividade realizada na quarta-feira, 26 de agosto de 2015.

Nesse dia duas turmas da Escola Joaquim da Silva Peçanha visitaram a UERJ. Pela manhã, uma turma com aproximadamente 30 crianças com idades variando entre 9 e 11 anos. De noite, uma turma muito mais heterogênea: diversas idades, raças, cores, crenças, gêneros; e, talvez, algo em comum: a busca de um tempo perdido. Participaram também alunos pertencentes à turma 1 da disciplina Pesquisa e Prática Pedagógica I - Estudos da Infância, do Curso de Pedagogia da UERJ; a cargo do Professor Sammy Lopes. Apesar do tempo um pouco corrido: o trânsito tinha atrasado em muito a chegada dos alunos à universidade; o vizinho estádio do Maracanã estava alvoroçado perante a iminência de um clássico... Foi possível estender a experiência por mais ou menos uma hora.

Alguns dos alunos (ainda) não leem. Outros ainda não escrevem. Walter partiu do princípio de que todos são igualmente capazes: escreveu no quadro um fragmento do filósofo grego Heráclito, o 123; grafando as três palavras gregas que o conformam (PHYSIS KRYPTESTHAI PHILEI) e uma tradução ao português: "A natureza ama ocultar-se". Propôs, então, algumas atividades que todos os alunos fizeram com entusiasmo: substituir "a natureza" por outro sujeito que, na consideração de cada um, ame ocultar-se. Depois, se tratava de mudar o predicativo "ocultar-se" por algum outro e, finalmente, compor um fragmento próprio articulado por um sujeito, um verbo conjugado e um infinitivo como predicativo a partir de todas as

\footnotetext{
5 Projeto de extensão, ensino e pesquisa desenvolvido em parceria entre o Núcleo de Estudos de Filosofias e Infâncias (NEFI) do Programa de Pós-Graduação em Educação da UERJ e duas escolas municipais de Duque de Caxias: a Joaquim da Silva Peçanha e a Pedro Rodrigues do Carmo. Detalhes sobre o projeto, no livro Kohan, W.; Olarieta, B. (orgs.) A escola pública aposta no pensamento. Belo Horizonte: Autêntica, 2012 ou no site www.filoeduc.org.
} 
palavras emanadas da turma. No meio, os alunos compartilhavam suas produções e algumas motivavam a troca de ideias. O encontro terminou com os estudantes lendo os fragmentos que produziram. Durante cada uma das fases do trabalho, as enunciações foram registradas no quadro, montando um mosaico do que foi dito.

\section{Uma experiência de infância, com jovens e adultos}

Estranho quando estamos diante de algo que temos experimentado e, curiosamente, parece renovar-se na sensação de uma primeira vez. A primeira vez da segunda, a primeira vez da terceira, a primeira vez das muitas vezes que nos reunimos numa roda de conversa para mais uma experiência de pensamento com crianças, jovens e adultos.

Desta vez, já no final de um inverno, o cenário não é a sala de filosofia da escola, mas uma sala ampla, que chamamos de ateliê. É uma quarta-feira de agosto, Maracanã pertinho, aguardando milhares de torcedores para uma decisão entre Vasco e Flamengo. Nós também vamos começar uma partida. Não é o futebol...

Estamos reunidos, estudantes e professores de duas instituições públicas, uma escola da Baixada Fluminense, a Joaquim da Silva Peçanha e uma universidade, a do Estado do Rio de Janeiro. Ocupamos uma das salas do curso de Pedagogia em dois momentos. Também não é uma sala qualquer: chama-se "Ateliê de Infância e Filosofia: Dr. Matthew Lipman" (ATIF). É uma sala especial, acondicionada com certa geografia mais infantil do que o habitual nas salas de aula das universidades. Ela está situada no décimo segundo andar, o mais alto, desse alto prédio em Vila Isabel, zona norte do Rio de Janeiro, onde funciona a maior parte dos cursos desse campus. É de noite, os estudantes da Educação de Jovens e Adultos (EJA) chegam curiosos, com celulares na mão, fotografando, se autofotografando... Olham, se olham, com que sofreguidão buscam ver-se a si mesmos, capturar algo do mundo que, nessa noite, abriu-lhes uma porta.

Crianças e jovens de escola pública na universidade pública? São presenças raras circulando naquele lugar onde se discutem questões da educação. Eles 
chegam, ocupam um espaço, começam a habitá-lo em modo de convite. Convite a pensar o que nunca havíamos pensado, a fabricar um tempo de abertura à novidade do mundo, à criação de uma disponibilidade a ser surpreendido, surpreender. Uma das estudantes de pedagogia - depois de acompanhar a meninada para tirar fotos do Maracanã, desde uma sacada no final do corredor disse algo muito interessante que dá o que pensar: "Eu nunca tinha olhado o Maracanã desse jeito!" O relato da estudante é de surpresa, de espanto. O Maracanã, vizinho do campus da universidade, compondo a paisagem da região, visto de maneira singular desde uma das sacadas do prédio. O que provoca o estranhamento da estudante, tornando desconhecido algo que, até então, sempre estivera ali? Seu estranhamento talvez seja o estranhamento de si mesma, da forma nova de perceber o mundo, dos movimentos que desenha na sua atual caminhada. Um olhar, uma escuta, os sentidos em rotação, circularidade...

O projeto de filosofia na escola "Em Caxias a filosofia en-caixa?" tem sido um convite permanente a estranhar o mundo, a habitá-lo de uma forma diferente da que temos habitado. Seria essa uma das feições mais importantes desse projeto, na medida em que renova um certo convite, uma abertura ao frescor, à surpresa de uma primeira vez? É essa uma experiência de infância? Seria, então, o projeto um convite a reencontrar a infância antes do que a formá-la?

A filosofia, da forma como a temos vivido, tem apostado nos encontros, nos deslocamentos. Quando nos deslocamos, estamos expostos; muitas vezes o que nos resta é apenas nudez, o som dos rasgos das vestes inexoravelmente ficando para trás. Um som, convocação à dança da vida, uma filosofia dançarina (Bardet, 2015), que desenha movimentos com o deslocamento dos corpos para compor seus próprios enigmas. Tem algo de inaugural, de surreal. Derrete sutilmente um relógio, pinceladas de Dalí, criando um tempo de acolhida ao que não sabemos e, muitas vezes, impotentes, fracassados, não temos como nomear. Para abraçar uma realidade, acolhendo a potência dos sonhos, há que se desafiar o tempo da celeridade do mundo, a velocidade a que somos impelidos a fazer nossos movimentos. 


\section{Um tempo de sonhar a raridade de um projeto}

Qual é o tempo de sonhar? "Ir à UERJ me fez lembrar dos meus sonhos". São as palavras de Nadja, uma estudante da EJA, compartilhando com o grupo da escola as sensações que o encontro na universidade the haviam despertado. Despertar para deixar que os sonhos, os delírios possam ter voz e escuta para o que eles nos apontam de nós mesmos, dos sentidos que temos construído no percurso como estudantes, professores, seres humanos neste "mundo vasto mundo" (Drummond de Andrade, 2013, p. 11) ... Tudo isso nos leva a pensar que o exercício de filosofar na escola também pode ser um exercício de habitar o impossível como se fosse possível, ou ainda necessário. Talvez por isso narrar o que tem nos acontecido e afetado no projeto seja um exercício tão desafiador, tão bonito... Há que se encontrar palavras, uma sintaxe, uma linguagem capaz de abrigar a intensidade desses acontecimentos...

Neste momento, ressoam com força as palavras da professora Rosimeri de Oliveira Dias, em abril de 2015, no dia da qualificação do projeto de doutorado de nossa colega do curso de doutorado Vanise Dutra, coordenadora do projeto na escola Joaquim da Silva Peçanha. Por muitas vezes, a professora destacou em sua avaliação que um projeto de filosofia de uma universidade numa escola é "raro". O que faz desse projeto algo tão raro? O estranhamento e admiração da professora chamam à atenção: para os que fazem parte do projeto ele não nos parece tão raro; ao contrário, ele se tornou parte de nós. O que essa sensação de raridade pode nos dar a pensar sobre a relação entre escola e universidade e sobre a relação com o que temos lido, estudado e experimentado, a partir do conhecimento disponível no campo da educação em contraponto com nossas vivências? A filosofia tem incessantemente nos colocado à prova.

Quando nos reunimos com os estudantes para pensarmos juntos, muitos dos conceitos que lemos nos livros, em nosso percurso formativo, são postos em questão. Pensamentos, veiculados como verdades, começam a desmoronar como 
castelos construídos à beira do mar... As perguntas que vão surgindo, muitas vezes, não encontram respostas: "Como se aprende a imaginar?" "Imaginar e pensar são a mesma coisa?" "Qual a diferença entre pensar, imaginar, sonhar?" "O que faz um coração se apaixonar?" Quem se atreverá a responder perguntas dessa natureza? E o mais interessante não está nas respostas que possamos pensar, mas no exercício de escutar o outro, escutar como uma forma de acolher o que o outro nos traz, nos oferece, doa. Escutar não seria uma forma de doar-se? Quem sabe um dom... Num mundo que tem privilegiado a cognição, a acumulação de conhecimentos para competir cada vez mais, há espaço para uma educação atravessada por uma filosofia enquanto exercício de escuta, de atenção? Uma filosofia do pensar, do imaginar, do sonhare Será essa uma primeira raridade do projeto? Se colocar perguntas sem resposta e procurar pensá-las mesmo sabendo da impossibilidade de respondê-las? Ou a sua raridade terá a ver com afirmar para a função docente um espaço que tem a ver com escutar e acolher o outro muito mais do que com formá-lo?

\section{A raridade das condições, as condiçōes da raridade}

Lucas, estudante da EJA, nos ajuda a perceber uma outra forma de raridade do projeto. Assim como outros estudantes, ele visitou pela primeira vez o campus da universidade. Sua preocupação, a princípio, antes da visita, era com o uniforme da escola pública: "Professora, vai ter que ir de uniforme?" Prontamente respondemos que sim, que todos deveriam estar com a camisa da escola. Respondemos à pergunta dele quase automaticamente, sem pensar nela...

Depois de realizada a visita à UERJ, durante a semana voltamos a nos reunir para mais uma experiência de pensamento. Conversamos sobre o que tinha acontecido. Lembramos o que tinha nos afetado. Lucas, novamente, trouxe a questão do uso do uniforme, relacionando dois aspectos do encontro muito potentes para pensar os movimentos de aproximação/afastamento entre universidade e escola que o projeto de filosofia vem provocando. Vamos ler o que escreveu Lucas e entregou para Edna, uma semana após a experiência: 
Achei fantástico a maneira que nós alunos fomos tratados e realmente me surpreendi com a maneira que fomos acolhidos. Ao chegar na sala e perceber que os professores e alguns alunos que cursam filosofia na faculdade estavam usando o uniforme da minha escola me deixou sem palavras, foi incrivel e muito reconfortante. Reconfortante porque quando eu fiquei sabendo que iríamos na universidade, logo questionei o uso do uniforme, porque em minha experiência de estudante de escola municipal, usar uniforme e ser tratado mal e com indiferença é algo normal! Meu erro foi achar que seria tratado do mesmo jeito na universidade. Erro que fez com que me sentisse envergonhado por ter questionado o uso do uniforme.

Quando Lucas chegou, encontrou os professores do projeto vestindo o mesmo uniforme que ele vestia na escola. Os professores da universidade vestiam o uniforme escolar. Ele disse ter se surpreendido pela forma da acolhida: "sem palavras", "incrível", reconfortante", assim se sentiu Lucas. Eis que sua pergunta inicial tornou-se mais clara para nós: ele duvidava em ir de uniforme escolar porque pensava que, com ele, seria discriminado dentro da universidade. Tamanha foi sua surpresa quando não apenas não se sentiu discriminado, mas os próprios professores do projeto vestiam o mesmo uniforme que o seu. Comentando seu depoimento sobre a experiência, Lucas acrescentou que ela foi uma forma de "viver a igualdade". Conversar, versar com o outro, escutar o outro como condição para escutar a si mesmo. Vamos agora ler o Lucas a respeito de suas sensações durante a aula:

Não tenho nem o que dizer sobre a aula, foram tantas coisas que ouvi, que me deixaram completamente em êxtase, eu saí da sala de aula meio atordoado e muito mais pensativo do que de costume. Ao final da aula ficou uma pergunta no ar, uma pergunta que realmente não queria se calar. E durante alguns dias da semana do encontro eu pensei muito sobre essa pergunta e no que eu poderia ter respondido no momento em que ela foi perguntada em sala de aula, mas não consegui infelizmente, pois me faltou coragem no momento. Admito. Porém ao saber que deveria escrever sobre isto, pensar e responder com mais calma [...] 
"Completamente em êxtase". Ele saiu da aula atordoado, muito mais pensativo que habitualmente. Pensava sobre o que tinha acontecido a partir de uma experiência de igualdade. Para essa experiência poder acontecer, a escuta do outro parece uma condição. Seria possível viver em igualdade sem experimentar uma escuta? Como viver a igualdade sem a escuta e a acolhida de professores que parecem carregar nos braços a pergunta de habitantes de outros espaços como se carrega uma criança, uma vida que acabou de nascer? Ao final da aula, fica uma pergunta, diz Lucas, que o faz pensar durante a semana toda. A aula termina e fica uma pergunta. O pensamento começa... ou recomeça.

Quando escutamos o Lucas já é de noite em Duque de Caxias, mas parece que também o dia está só começando. Assemelha-se a um momento de nascimento, à primeira vez das muitas vezes que insistem em apresentar um começo, em reivindicar um lugar, um tempo, um instante, um parto com dor e alegria, fruto de uma espera amorosa...

Talvez a filosofia na escola tenha a ver também com um estranho e enigmático jeito grávido de viver, uma disponibilidade à espera de algo que poderá nascer a qualquer instante. As experiências de pensamento são exercícios de abertura à novidade do mundo, à da vida. A qualquer momento algo pode acontecer, uma pergunta, um olhar, um gesto, um mar se abre... De repente, nada mais poderá ser como antes... Uma primeira vez, a primeira vez...

\section{Há um método para pensar?}

O que nos fazem pensar estas experiências com crianças e adultos de escolas públicas dentro da universidade? Quais são as condições dessas experiências? Algo parece nítido: não se subestimou a inteligência de ninguém (Rancière, 2003). O nosso companheiro Daniel o tinha colocado em suas palavras na avaliação da primeira experiência, pela manhã: "Visto que chegamos a conclusões muito próximas às das crianças, me parece evidente que crianças e adultos pensam igualmente". 
Costuma-se considerar que para a Educação de Jovens e Adultos, que tem alunos ainda em processo de alfabetização, não seria adequado um professor pedir para criar e reformular frases e perguntas com verbos no reflexivo - no estilo de um filósofo da antiguidade (Heráclito) -: tratar-se-ia de uma atividade inadequada e de difícil compreensão. Para muitos, colocar esses temas, desse jeito, confundiria os alunos (tanto crianças, jovens ou adultos), e a proposta soaria complexa e, portanto, sem uma "didática eficaz"...

Lucas ao mesmo tempo confirma e desmente essas considerações: ele confirma ter se sentido atordoado, aturdido... Porém, essa sensação, longe de paralisar seu pensamento, o fez continuar pensando a semana toda na pergunta que ficou pendente nessa aula. Muitos métodos de ensino e aulas de didática nos "ensinaram" a propor e a pensar atividades direcionadas a diferentes grupos, pressupondo que cada um teria uma limitação ou um nível de cognição x ou y que deveríamos respeitar e levar em consideração ao preparar uma aula ou qualquer coisa a ser apresentada. E por isso mesmo muitos poderiam crer absolutamente desapropriado ou inconveniente propor perguntas e estruturas gramaticais "complexas" (escritas no quadro) a um grupo no qual muitos alunos ainda estão aprendendo a ler e a escrever. Mas será que toda essa ideia de método ou didática "adequada" valeria para a filosofia quando ela é entendida em sua dimensão de experiência do pensamento?

Para responder essa pergunta, faz-se interessante seguir com outro ponto de convergência que pode ser notado na experiência vivida: a hospitalidade praticada, não só por parte do anfitrião como dos próprios hóspedes. Estamos nos referindo à reciprocidade dessa hospitalidade (Derrida, 2003). A aceitação do convite para pensar essas questões, por parte dos convidados-hóspedes da escola que estavam na UERJ, foi uma coisa que chamou a atenção. Inclusive, nesse espaço que aparentemente era "nosso", nós (os "universitários") poderíamos ser considerados de certa forma como estrangeiros. Às vezes com os estrangeiros nos comportamos de maneira mais tímida, talvez desconfiada... No entanto, na experiência, os convidados da escola, ainda que à primeira vista parecessem estar mais recuados do que "à vontade", estavam também dispostos, atentos e 
receptivos às propostas sugeridas, às perguntas feitas, à dinâmica da experiência. Deixaram-se levar pelo convite porque também foram hospitaleiros com os seus anfitriões-estrangeiros. Eles, ainda que sendo nossos convidados, também nos receberam muito bem.

O curioso é que o coordenador dessa experiência, Walter Kohan, é de fato, estrangeiro. Ele trouxe uma frase grega de um filósofo muito antigo e igualmente estrangeiro, e sua leitura, exemplos e elucidações foram entoadas com seu particular modo bilíngue de falar. A maioria dos estudantes não o conhecia (apenas alguns tinham compartilhado alguma atividade anterior, seja na escola ou na universidade): o que o tornava "estrangeiro ao quadrado". Ainda assim, os alunos acolheram a sua proposta e participaram, fizeram perguntas, se envolveram, alguns mostrando-se entusiasmados e cômodos, embora tímidos, como Lucas.

Essa questão da hospitalidade está, dentre muitos outros motivos, estreitamente relacionada à filosofia pela própria etimologia da palavra philía (amizade). Francisco Ortega, por exemplo, nos lembra que:

O tratamento de phílos corresponde ao comportamento diante do estrangeiro-hóspede. (...) Philein também possui o sentido de exprimir a hospitalidade, de receber estrangeiros, e de se beijar, como um sinal de reconhecimento entre os phíloi (...) Philein determina a conduta de quem recebe o estrangeiro (xenos) na sua casa e o trata segundo os costumes. Entre o estrangeiro e o hóspede se institui um vínculo: o philótes, realizado num ato solene, que converte os contratantes em phíloi, obrigando-os a cumprir a reciprocidade implícita na relação de hospitalidade (ORTEGA, 2002: 18).

Voltemos à nossa pergunta anterior: "será que a ideia de método "adequado" valeria para a filosofia entendida como uma experiência de pensamento?". Pensemos no acolhimento do convite. Pensemos também na hospitalidade e na igualdade das inteligências como princípios. Será que se trata de estabelecer um método para a filosofia ou de gerar as condições para que o pensamento possa ser experimentado? E quais seriam essas condições? E como gerá-las, cuidá-las, alimentá-las? 
Se a filosofia tem a ver com philos e philía, e se partimos desse compartilhar algo de interesse (inter-esse; o que está entre nós) para promover qualquer encontro (seja na escola, na universidade ou em outro lugar), não pareceria um pouco "sem sentido" pensar que o seu amigo, aquele hóspede, quem você convida, recebe e acolhe (e que te acolhe, recebe e convida de volta), precisaria de um caminho que você outorgasse para poder jogar o jogo ao qual você o está convidando?

Afinal, quais seriam as "condições mínimas" para que as propostas de experiências de pensamento sejam "aceitas", além do desejo comum de trocar e pensar com o outro? No caso da filosofia, essas condições seriam de qual tipo? Políticas? Epistemológicas? Pedagógicas? Cognitivas? Afetivas? Ou será que a única condição da filosofia seria o próprio exercício do filosofar enquanto tal, isto é, uma partilha de um desejo de saber, entre amigos? O que se precisaria, para promover uma experiência de pensamento filosófico, além do pressuposto de uma igualdade (de inteligências e desejos) entre anfitriões, estrangeiros e hóspedes? Seriam essas três figuras como formas, máscaras e fantasias de um professor de filosofia? E os estudantes, de que precisariam além dessas três figuras?

Talvez alguma dessas perguntas tenha sido atravessada na própria experiência quando Leonardo, 18 anos, aluno da EJA, pergunta-se como é possível comunicar um sentimento uma vez que ele sente uma coisa e o outro sente uma outra coisa que ele desconhece. Duvida e, finalmente, lança a pergunta:

Leonardo: Por que o sentimento compartilha-se?"

Walter: Alguém tem alguma ideia de como responder esta pergunta?

Elenyldo: Por que se ama!

Luiz: o sentimento é uma terra que ninguém anda.

Luiz é um senhor de uns 50 anos. Quase não piscou durante a experiência. Sua fala provocou gestos de admiração, afeição, espanto. Mas talvez seja hora de 
voltar ao Lucas que também fez referência a esta pergunta no texto que nos entregou por escrito alguns dias depois das experiências. Eis seu testemunho:

Porque o amor compartilha-se? Antes de mais nada, não deveria haver nenhum tipo de "porque" em uma frase relacionada ao amor. $O$ amor já é um sentimento muito confuso, as pessoas usam tantos "porquês" e "interrogações" ao falar sobre o amor que acabam complicando o que já é complicado o suficiente por natureza. Então reformulando a frase original título, ficaria: "o amor compartilha-se." Parece até que as palavras ficaram mais leves sem o peso das perguntas não é mesmo? Mas enfim, vamos ao que interessa; logo quando se descobre o amor, você precisa amar, você precisa compartilhar esse amor que vive dentro de você, porque ele tem essa necessidade. O amor nunca vai precisar pedir nenhum tipo se permissão para ser compartilhado, até porque ele não precisa de permissão para fazer o que ele nasceu para fazer. Na verdade, ele não precisa de permissão para nada, o que o amor quer, o amor faz, sem mais! O amor só precisa de outro amor; como as sombras precisam da luz, ele só precisa ser amado por outro alguém. Ele precisa que esse alguém se sinta feliz apenas por conseguir senti-lo. E por isso ele deve ser compartilhado! [...].

As palavras ficam mais leves sem o peso das perguntas, afirma Lucas. E responde. Tira o signo de interrogação e, com ele, seus medos e seus temores. Responde. Curiosamente, com outra pergunta. Eis o jogo do pensamento. Não há como parar. Lucas fala do amor e parece também estar falando da filosofia, afinal, uma forma do amor. Colocamos "filosofia" onde Lucas diz "amor": quando se descobre a filosofia você precisa filosofar, você precisa compartilhar essa filosofia que habita dentro de você. É uma necessidade. A filosofia não precisa de nenhum tipo de permissão para ser compartilhada, para fazer o que ela nasceu para fazer. Aliás, a filosofia não precisa de permissão para nada: o que ela nasceu para fazer, ela faz. A filosofia só precisa de outra filosofia. O filósofo, a filósofa só precisa de outro filósofo ou filósofa. Ela só precisa que o outro sinta-se feliz apenas por conseguir senti-la. Por isso ela deve ser compartilhada? 
Talvez sem estar pensando nela, Lucas recria a etimologia e as condições da filosofia que tínhamos apresentado alguns parágrafos atrás. Seu depoimento é quase uma exortação à filosofia. Como o de sua colega e amiga Keteleny que também nos passou um texto escrito, exuberante e indescritível, como suas próprias sensações. Eis seu depoimento:

Relembrando o que falaram na filosofia dá escola: Lucas disse que ficou feliz por ter presenciado outras pessoas usando a blusa da escola. Confesso que foi um gesto carinhoso e confortante. Antes de entrar no prédio já podia sentir que tudo iria sair como o planejado, e se não saísse, com certeza ficaria melhor do que eu esperei. Me senti abraçada mesmo não sendo abraçada. Me senti mais feliz ainda por estar com pessoas que te fazem sentir feliz, e ter a sensação de sinceridade em cada gesto e olhar. São pessoas que fazem diferença neste mundo, não esperam acontecer, mas fazem acontecer. Aquele professor argentino, não recordo o nome, mas só pelas qualidades já vai saber quem é. Excelente pessoa, o amor por ensinar corre pelas veias dele. Cada exercício de pensamento repousava fragmentos bons sobre mim. Sai dali com a alma regada, florida. Por mais que atrás estivesse diversos sons de pessoas falando, meu interior reinava o silêncio mais aconchegante para imaginação nadar nas frases lançada anteriormente. Posso dizer que vários textos vão sair a partir dessa aula. Única palavra que consigo encaixar para esse dia é: Indescritível. As mais belas palavras não poderão descrever e expressar o quanto foi exuberante. De todo meu coração, sou grata. Anseio ansiosamente por mais encontros como aquele. Continuem assim, florindo outras vidas.

É para sair com a alma regada mesmo, florida. Tem razão, Keteleny, vários textos estão saindo a partir dessa aula, indescritível, como a filosofia. Somos gratos e, esperamos, ansiosamente, novos encontros. Enquanto isso, ficamos em silêncio, o mais aconchegante possível, nadando nas frases de Keteleny, Lucas, Elenyldo, Luiz, Leonardo e tantos outros que recriam, em cada encontro, o rito da filosofia, da amizade, do amor ao pensamento e ao mundo que se abre com cada encontro. 


\section{Referências bibliográficas}

BARDET, Marie. A dança da filosofia. Um encontro entre dança e filosofia. São Paulo: Martins Fontes, 2015

DERRIDA, J. Anne Dufourmantelle convida Jacques Derrida a falar da Hospitalidade. São Paulo: Escuta, 2003.

DRUMMOND DE ANDRADE, Carlos. Poema de sete faces. In: Alguma poesia. São Paulo: Companhia das Letras, 2013.

KOHAN, W.; OLARIETA, B. (orgs.) A escola pública aposta no pensamento. Belo Horizonte: Autêntica, 2012.

ORTEGA, Francisco. Genealogias da amizade. São Paulo: lluminuras, 2002.

RANCIÈRE, Jacques. O mestre ignorante. Belo Horizonte: Autêntica, 2003. 